\title{
Meio ambiente: a extensáo na Operaçáo Forte dos Reis Magos do Projeto Rondon em Acari, Rio Grande do Norte
}

Environment: university extension in Operation Forte dos Reis Magos of Rondon
Project in Acari, State of Rio Grande do Norte, Brazil

\section{RESUMO}

$\mathrm{Na}$ sociedade atual, é fundamental o debate acerca do meio ambiente. Assim, as perspectivas acadêmicas e científicas se expandem pela extensão universitária, gerando, inclusive, novos pressupostos e resultados. Diante disso, uma das oficinas do Projeto Rondon, Operação Forte dos Reis Magos 2016, no município de Acari, Rio Grande do Norte, foi a de meio ambiente, que ocorreu no ensino infantil, ensino fundamental, ensino médio e na capacitação docente, alcançando os professores, alunos e a sociedade local. As oficinas buscaram conscientizar, problematizar e capacitar sobre o meio ambiente associado à sociedade local e suas preocupaçóes. Para isso, trabalhou-se com levantamento bibliográfico acerca da extensão universitária e do meio ambiente, que alicerçou a construção do material apostilado utilizado na aplicação das oficinas. Este texto tem como objetivo principal apresentar a experiência com essas oficinas em uma atividade de extensão no interior do Rio Grande do Norte. Os procedimentos metodológicos foram: levantamento bibliográfico, realização das oficinas de extensão e sistematização dos resultados. Os principais resultados foram quanto à conscientizaçáo acerca do meio ambiente, visto que a realidade na qual o município está inserido se relaciona diretamente com a questão ambiental, sobretudo acerca do acesso à água e sobre a vegetação.

Palavras-chave: Educação. Meio ambiente. Extensão universitária. Projeto Rondon.

\begin{abstract}
In today's society, the debate about the environment has fundamental importance. Thus, the academic and scientific perspectives are expanded by the university extension, generating, also, new assumptions and results. Therefore, one of the workshops of the Rondon Project, "Operation Forte dos Reis Magos 2016", in the municipality of Acari, State of Rio Grande do Norte, Brazil, was
\end{abstract}

Pedro Henrique Carnevalli Fernandes

Doutor em Geografia pela Universidade Estadual de Maringá, Paraná, Brasil; professor da Universidade Estadual do Norte do Paraná, Campus Cornélio Procópio, Paraná, Brasil (pedrofernandes@uenp.edu.br).

Luan Vitor Alves de Lima

Mestrando em Genética pela Universidade Estadual de Londrina, Paraná, Brasil (luan_vitorr@hotmail. com). 
the one about "environment", which took place in early childhood education, elementary school, and secondary school and teacher training, reaching out to teachers, students and local society. The workshops of environment sought to raise awareness, problematize and empower the environment associated with local society and its concerns. For this, we worked with a bibliographical survey about the environment and university extension that supported the construction of the booklet material used in the application of the workshops. This paper has as main objective to present the experience with the environmental workshops in an extension activity in the interior of Rio Grande do Norte. The methodological procedures were: bibliographical survey, accomplishment of extension activities and systematization of the results. The results were of environment awareness, since the reality in which the county is inserted is directly related to the environmental issue, especially regarding access to water and about the vegetation.

Keywords: Education; Environment. University Extension. Rondon Project.

\section{INTRODUÇÃO}

Atualmente, é imprescindível que a universidade ultrapasse os seus limites e atue, intensamente, nas diferentes comunidades de forma a contribuir com a emancipação social. Nesse sentido, a extensão universitária desempenha papel central, uma vez que ela é uma forma de interaçấo entre a universidade e a comunidade. Há, assim, uma relação dupla entre os acadêmicos e a comunidade local atendida quanto ao conhecimento transmitido, ou seja, em forma de retroalimentaçáo, como as reais necessidades, anseios e aspiraçôes. Então, a extensão universitária se configura como o processo educativo, cultural e científico que articula o ensino e a pesquisa, isso ocorrendo de forma indissociável, e viabiliza a relação entre universidade e sociedade (NUNES; SILVA, 2011).

O objetivo deste artigo é apresentar a experiência em extensão na realização das oficinas de meio ambiente na "Operação Forte dos Reis Magos" do Projeto Rondon, no município de Acari, no Seridó do Rio Grande do Norte. Os objetivos específicos foram: contribuir 
com o debate teórico proposto pela academia sobre o meio ambiente, demonstrar os resultados e a experiência na aplicação da oficina e, por fim, refletir acerca da extensão universitária em consonância com a realidade do interior do estado.

Os procedimentos metodológicos para a realização deste artigo foram: levantamento bibliográfico acerca da extensão universitária e do meio ambiente e de assuntos transversais a eles, sobretudo considerando o meio ambiente e a educação; descrição e análise da preparação do projeto de extensão; descrição, análise reflexiva dos resultados e registro fotográfico da realização de oficinas de extensão durante a Operação Forte dos Reis Magos do Projeto Rondon em Acari; e, finalmente, sistematização dos resultados na elaboração da redação final deste artigo.

O Rio Grande do Norte é uma Unidade da Federação brasileira pertencente à Regiáo Nordeste, e faz fronteira com a Paraíba e o Ceará. As faces Norte e Leste do Estado são litorâneas, com extensão de 410 quilômetros, banhadas pelo Oceano Atlântico. A área do Estado é de 52.811 quilômetros quadrados e a população absoluta de 3.168.027 habitantes, gerando uma densidade demográfica de 60 habitantes por quilômetro quadrado (IBGE, 2010; RIO GRANDE DO NORTE, 2018).

O Estado possui 167 municípios, sendo que Natal, a capital, é o maior demograficamente, com pouco mais de 803 mil habitantes (IBGE, 2010). Os demais municípios do Rio Grande do Norte são considerados demograficamente pequenos, com exceção de Mossoró (260 mil habitantes) e Parnamirim (202 mil habitantes). O Estado é dividido geograficamente em quatro Mesorregióes: Leste Potiguar, Agreste Potiguar, Central Potiguar e Oeste Potiguar (IBGE, 2010).

Os indicadores sociais e demográficos do Rio Grande do Norte estão em fase de transição social e demográfica. Todavia, ele ainda possui problemas sociais, como, por exemplo, a alta taxa de mortalidade infantil - 44,8 em mil nascidos vivos - uma das cinco piores do Brasil. Além disso, a expectativa de vida ao nascer é de quase 70 anos, três anos a menos que a média nacional, e o Índice de Desenvolvimento Humano (IDH) - 0,684 - é considerado baixo (IBGE, 2010; RIO GRANDE DO NORTE, 2018). 
O município de Acari está localizado na Mesorregião Central Potiguar e na Microrregião do Seridó Oriental (IBGE, 2010), possuindo, portanto, características típicas do Sertão. A Figura 1 apresenta uma vista parcial da cidade de Acari, sendo possível perceber que ela se encontra conectada, diretamente, com uma série de elementos físicos, como relevo, vegetação e recursos hídricos.

Figura 1 - Vista parcial da cidade de Acari-RN

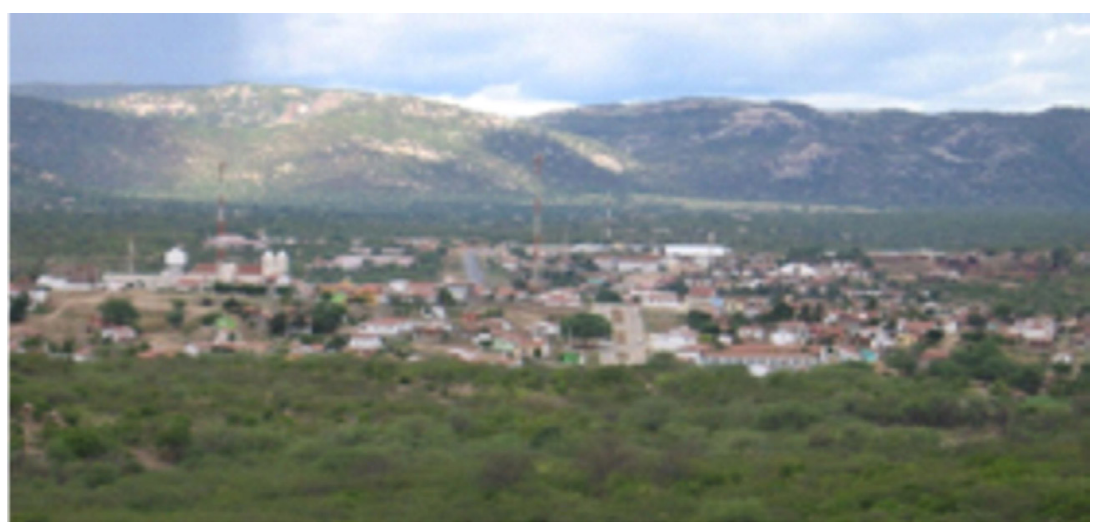

Fonte: Flickr (2018).

O município tem 11.035 habitantes, sendo que cerca de $80 \%$ residem em área urbana (IBGE, 2010), e compóe o Polo Seridó, reconhecido pelo turismo rural baseado na Caatinga (RIO GRANDE DO NORTE, 2018). A economia local se alicerça nos serviços (50\%) e na pecuária e agricultura (40\%), sendo que os indicadores sociais mais graves são: IDH baixo $(0,679)$, ausência de coleta de esgoto em 25\% dos domicílios, rendimento mensal per capital baixo ( $\mathrm{R} \$ 328,00)$ e 62\% da população em situaçáo de pobreza (ACARI, 2018).

\section{O Projeto Rondon e a Operação Forte dos Reis Magos}

O Projeto Rondon surgiu no Regime Militar (1964-1985) com o lema "Integrar para não entregar", uma vez que as regióes brasileiras do Centro-Oeste, do Norte e do Nordeste eram consideradas distantes do Sul e Sudeste do Brasil e, por conseguinte, pouco conhecidas e exploradas. A primeira operação, denominada de "Operação Zero", aconteceu em julho de 1967 no Território Federal de Rondônia e 
contou com uma equipe de trinta universitários e dois professores (RONDON, 2018).

Em 1968, essa iniciativa foi institucionalizada por meio do Decreto no 62.927, de 28 de junho de 1968, recebendo o nome de "Projeto Rondon”. Em 1989, o Projeto Rondon foi extinto. Após uma penúria de 15 anos, o Projeto Rondon foi reativado em 2004, pelo presidente Luiz Inácio Lula da Silva, após uma proposta de reformulação realizada pela União Nacional dos Estudantes (UNE). No ano seguinte, em 2005, aconteceu uma operaçáo no Estado do Acre, com a supervisão do Ministério da Defesa e do Governo Federal, denominada de "Operaçáo Acre" (RONDON, 2018).

Os atuais objetivos do Rondon são: proporcionar ao estudante universitário conhecimento de aspectos peculiares da realidade brasileira; contribuir com o fortalecimento das políticas públicas, atendendo às necessidades específicas das comunidades; desenvolver no estudante universitário sentimentos de responsabilidade social, espírito crítico e patriotismo; contribuir para o intercâmbio de conhecimentos entre as instituiçóes de ensino superior, governos locais e lideranças comunitárias. (RONDON, 2018).

A Operação Forte dos Reis Magos foi realizada entre 8 e 24 de julho de 2016, em dez municípios do Estado do Rio Grande do Norte, entre eles, Acari. Nessa operação, 21 Instituiçôes de Ensino Superior (IES) participaram, sendo duas por município mais uma equipe exclusiva para a comunicação social. O nome da operação foi uma homenagem ao ponto turístico mais relevante do Rio Grande do Norte, o Forte dos Reis Magos, localizado em Natal (RONDON, 2018).

A passagem da Operação Forte dos Reis Magos do Projeto Rondon em Acari proporcionou uma série de oficinas extensionistas em diversas áreas do conhecimento, como educaçấo, meio ambiente, direitos humanos e justiça, cultura, trabalho, turismo, saúde, tecnologia, entre outras. Uma das oficinas desenvolvidas foi a intitulada "Meio Ambiente", sendo realizadas com alunos do Ensino Infantil, da rede pública municipal de ensino; com alunos do Ensino Fundamental e Ensino Médio, da rede pública estadual de ensino; e, com docentes do Ensino Fundamental e Ensino Médio da rede pública estadual de ensino. É importante destacar que algumas oficinas foram realizadas 
em ambiente externo aberto, com intuito de estar diretamente em contato com o meio ambiente. Considerando a multiplicidade das características e das vivências dos públicos estimados, os rondonistas utilizaram projeção, por meio de slides, vídeos e imagens, ampliando a abordagem da oficina.

\section{Meio ambiente, homem e educação ambiental}

É de caráter instintivo que as espécies busquem um sucesso reprodutivo a fim de se preservar no meio ambiente, mediante a pressão da seleção natural que conduz os seres vivos na busca desse sucesso (STEARNS, 2000). Assim, de acordo com o autor, os seres humanos não estão isentos dessa regra, pois também fazem parte da biodiversidade do planeta como os demais seres vivos. O ser humano está, enquanto espécie, cada vez mais explorando o seu habitat visando sua manutenção, reprodução e sobrevivência.

Mediante aos avanços tecnológicos, o ser humano busca compreender o meio ao qual está inserido, utilizando de recursos obtidos por meio dos próprios avanços tecnológicos (PITOMBO; LISBÔA 2001). Logo, com a domesticação das plantas e animais, na chamada Revolução Verde, foram geradas diversas modificações nas atividades humanas, ocasionando uma maior exploração dos recursos bióticos e abióticos, aumentando, por conseguinte, os impactos na natureza (CORTEZ; ORTIGOZA, 2009).

A sociedade humana, durante a sua história evolutiva, utilizou de diferentes recursos naturais para sobreviver, especialmente pela modificação no sistema de produção, como nos casos da Revoluçáo Industrial e da Revolução Capitalista. $\mathrm{O}$ crescimento populacional acelerado gerou diversos problemas devido à busca de maior produçáo de alimento e ao aumento de resíduos e degradação ambiental (AFONSO PINHEIRO; CARVALHO, 2003). Porém, a partir da década de 1960, esse crescimento começou a ser questionado, juntamente com a utilização inadequada dos recursos naturais, visando os efeitos do impacto ambiental. Durante a década de 1970, surgiu, então, o termo Educação Ambiental (EA), que "enfatiza a relação dos homens com o ambiente natural, as formas de conservá-lo, preservá-lo e de administrar seus recursos adequadamente" (UNESCO, 2005, p. 44). 
Além disso, a Conferência das Naçóes Unidas sobre o Meio Ambiente, celebrada em Estocolmo em 1972, definiu o meio ambiente como o "conjunto de componentes físicos, químicos, biológicos e sociais capazes de causar efeitos diretos ou indiretos, em um prazo curto ou longo, sobre os seres vivos e as atividades humanas" (UNESCO, 2005, p. 44).

A Política Nacional do Meio Ambiente (PNMA), estabelecida pela Lei $\mathrm{n}^{\circ}$ 6.938/81, define meio ambiente como "o conjunto de condiçóes, leis, influências e interaçóes de ordem física, química e biológica, que permite, abriga e rege a vida em todas as suas formas" (BRASIL, 1981).

Visando a importância de toda estabilidade ambiental, a Constituição Federal do Brasil de 1988, no Art. 225, apresenta que todos têm direito a um ambiente equilibrado, havendo a necessidade de conscientização de preservaçáo e garantia da qualidade de vida. Assim, visa, segundo inciso VI, "promover a educaçáo ambiental em todos os níveis de ensino e a conscientização pública para a preservação do meio ambiente" (BRASIL, 1988).

Com isso, tem-se a EA servindo como meio de conscientização para que os indivíduos compreendam como as suas atividades implicam no meio ambiente (UNESCO, 2005). A escola é o local fundamental para a construçáo do saber, sendo uma aliada para a conscientizaçáo e a aplicação da EA, tornando possível o desenvolvimento de uma visão biocêntrica nos alunos. Assim, a EA deve ser direcionada para a construção da:

$$
\begin{aligned}
& \text { Cidadania ativa considerando o } \\
& \text { seu sentido de pertencimento e de } \\
& \text { corresponsabilidade que, por meio } \\
& \text { da ação coletiva e organizada, busca a } \\
& \text { compreensão e superação das causas } \\
& \text { estruturais e conjunturais dos problemas } \\
& \text { ambientais na sociedade contemporânea. } \\
& \text { (SORRENTINO et al., 2005, p. 288- } \\
& \text { 289). }
\end{aligned}
$$

Como também, a prática da EA pode promover a formação de valores sociais ao exercício de uma cidadania e novos atores sociais:

Desafiar a exclusão social e reagir à organização social posta, criando novos 
espaços para a tomada de decisões, gerando uma autonomia para construir novos sentidos da existência humana, forjando uma cidadania de outra ordem. (JACOBI, 2003, p. 198).

A capacitação é crucial para o conhecimento ser difundido, assim a EA trabalhada desde os primeiros anos educacionais aumentam as chances de conscientização, uma vez que é mais fácil construir o conhecimento junto ao desenvolvimento da criança, do que desconstruir e modificar um conceito já criado em um adulto (MEDEIROS et al., 2011).

Com a reflexão de que o ser humano faz parte da fauna existente no planeta, a EA busca possibilidades de discussáo por meio de açóes mais profundas, de modo a tentar modificar conceitos, atitudes e a mentalidade das pessoas acerca do ambiente (RODRIGUES; LABURO, 2014) e visóes antropocêntricas (REIGOTA, 2002).

Discutir as açôes que intensificam os problemas ambientais, como poluição das águas e dos solos por resíduos químicos, contaminação do ar por gases poluidores e demais problemas são importantes nos diferentes níveis de ensino (SANTOS; SILVA, 2017). Também, é importante ressaltar que a educação não deve se estruturar apenas no ambiente escolar, mas sim em diferentes meios de propagação, principalmente na extensão universitária, contribuindo, assim, como mecanismo de conscientização para o equilíbrio do meio ambiente.

\section{As oficinas de meio ambiente na escola em Acari-RN}

Em Acari, no Seridó do Estado do Rio Grande do Norte, o relacionamento entre a sociedade local e o meio ambiente ocorre, principalmente, por meio do recurso hídrico. A maior atração turística do município é o Açude Marechal Dutra, conhecido como "Gargalheiras", inaugurado em 1959. Porém, desde 2010, ele encontra-se seco, recebendo poucos visitantes.

Além dessa perspectiva turística, o açude era fundamental para a alimentação de muitos moradores da Vila dos Pescadores, localidade próxima a ele. A Figura 2 apresenta os dois momentos: o primeiro, em 2009, demonstra o último momento em que o açude sangrou, fenômeno de transposição da água sobre a barragem, e o segundo, 
em 2016, apresenta a realidade atual de seca do açude. Como visto, o meio ambiente é fundamental na realidade local, sobretudo por fazer parte do imaginário, da cultura, da economia e dos hábitos e costumes.

Figura 2 - Açude Gargalheiras, Acari-RN, em 2009 e 2016

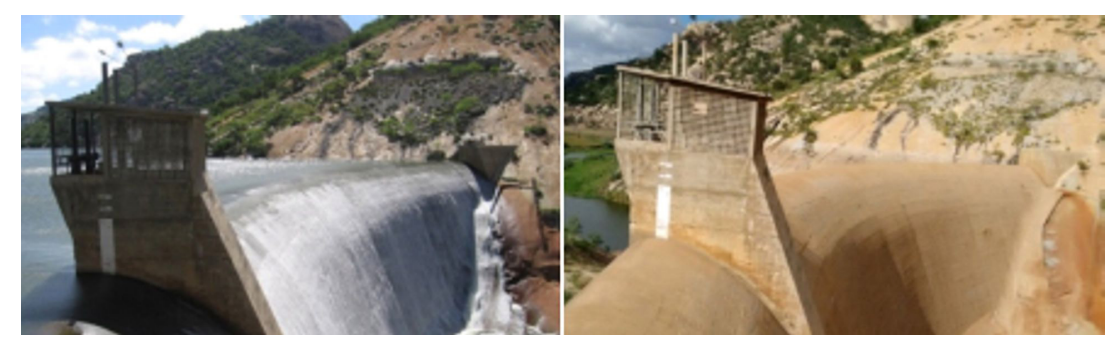

Fonte: Flickr (2018); Os autores (2016).

Como as oficinas de "Meio Ambiente" da Operação Forte dos Reis Magos 2016 ocorreram duas no Ensino Infantil, duas no Ensino Fundamental, duas no Ensino Médio e uma como capacitação docente, elas alcançaram professores, alunos e sociedade local. As oficinas buscaram conscientizar, problematizar e capacitar sobre o meio ambiente associado à sociedade local e suas preocupaçóes. Para isso, trabalhou-se com material apostilado, fundamentado com referências bibliográficas, e com atividades práticas.

Parece ser repetitivo todas as vezes que se fala sobre o meio ambiente. Os alunos passam boa parte da vida escolar escutando que devem preservar os recursos que a natureza oferece e minimizar os impactos das suas atividades. Portanto, falar sobre o tema para o público escolar se tornou um desafio, pois a abordagem precisa ser contextualizada de uma forma pedagógica diferente, principalmente nos alunos do ensino médio. Durante as oficinas realizadas com os alunos, foi possível perceber que eles possuíam um embasamento mediano sobre o meio ambiente, principalmente pelo fato de estarem passando por umas das piores crises hídricas do município.

Além dessa questáo, outro assunto relevante que apareceu no debate foi o impacto dos transgênicos, devido ao grande tabu que há sobre o tema. Mediante a curiosidade, entraram em debate argumentos prós e contras, evidenciando que há um equívoco para o entendimento de transgenia, visto que as suas reais definiçôes são distorcidas e 
propagadas, na maioria das vezes, sem embasamento científico. Para Piana (2013, p. 45), "os alimentos transgênicos geram polêmica devido ao risco que podem causar, então é importante que sejam adotadas medidas de segurança”. Assim, debater assuntos que são mais próximos dos alunos leva a uma reflexão mais profunda sobre o meio ambiente, gerando resultados positivos e proveitosos.

Nas oficinas realizadas na Educação Infantil, houve uma diferença na forma de trabalhar o conteúdo, pois foi preciso desenvolver uma linguagem mais dinâmica próxima da realidade dos alunos. Tendo um público de aproximadamente quarenta crianças, formou-se uma roda e todos se sentaram no chão e os rondonistas, no centro, iniciaram um diálogo interativo, pautado em uma metodologia mais dialogada. A participação ativa acabou por tornar o aprendizado mais eficiente, pelo qual enfatizou para os alunos a relevância do tema abordado.

Nas oficinas realizadas no Ensino Fundamental e no Ensino Médio, que atingiram 122 estudantes, houve uma contextualização geral sobre o tema "meio ambiente" com o intuito de achar o possível cerne a ser discutido. Foi quando o tema sobre insetos despertou curiosidade de todos, seguindo pelo levantamento das principais importâncias dos insetos para o equilíbrio ambiental, pautando a relevância da polinização, como também as relaçóes de insetos que são considerados "inimigos" do homem, tal como aqueles que são vetores de doenças.

Durante a realização dessas oficinas, foi relatada a existência de uma grande prevalência de doenças virais, como a Dengue e a Chikungunya. Assim, foi imprescindível desmistificar alguns mitos a respeito dessas doenças. A Figura 3 apresenta uma oficina aplicada em uma escola de Ensino Médio da rede estadual do Rio Grande do Norte, no município de Acari. 
Figura 3 - Oficina com alunos do Ensino Médio, Acari-RN

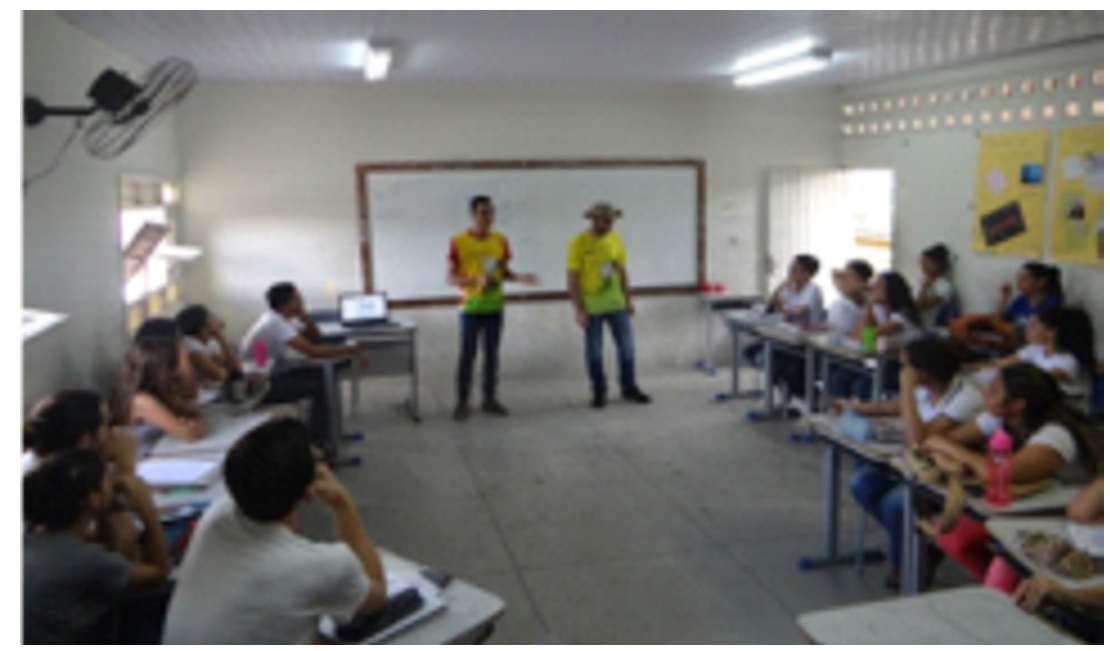

Fonte: Os autores (2016).

As oficinas de "Meio Ambiente" focaram na educação ambiental, demonstrando como que o acúmulo de lixo pode aumentar a incidência de doenças e como que a utilizaçáo de agrotóxicos pode ser muito danosa para o ser humano e para os demais animais. Nesse sentido, autores relatam que o saber das crianças sobre os animais pode influenciar nos seus comportamentos (SNADDON; TURNER; FOSTER, 2008), assim mitos podem ser criados, controlando a forma como as crianças veem os insetos (PROKOP; TUNNICLIFFE, 2008). $\mathrm{O}$ professor tem o desafio de desenvolver nos alunos o gosto por esses seres, sendo imprescindível superar tanto barreiras culturais como a própria distância filogenética entre esse grupo e o homem (SOUSA et al., 2013).

As problematizaçôes nos diferentes níveis educacionais fugiram do tradicional, em que apenas se fala da importância do meio ambiente utilizando tópicos como as famosas cores das lixeiras, os R's, reciclar e entre outros, visando, assim, uma contextualização próxima da realidade, fazendo com que os alunos se questionassem sobre as práticas utilizadas no meio ambiente. Por sinal, é, principalmente, no ambiente escolar que a EA ganha força, por meio dos professores e alunos que são os principais agentes de conservação e transformação do meio ambiente, visando melhorar as condiçôes do planeta. A EA 
na infância desperta na criança a consciência de preservação e de cidadania, pois, ela passa a entender e transmitir, desde cedo, que precisa cuidar e preservar e que o futuro depende do equilíbrio entre homem e natureza e do uso racional dos recursos naturais.

Somado a tudo isso, o professor exerce um grande papel social devido a sua atividade de propagação da educação, criando valores nos indivíduos ao qual atinge de forma direta e indireta. Formar alunos críticos é um desafio que faz dele um profissional dinâmico dentro dos mais variados contextos culturais. Assim, segundo Sousa e Santos (2010), avalia-se que capacitar educadores na EA é algo indispensável para modificar a percepção do ambiente.

Logo, o maior objetivo das oficinas realizadas na capacitação de professores foi apresentar ideias a serem desenvolvidas de maneira mais dinâmica e criar um debate entre os profissionais de como o tema ambiental estava sendo aplicado, sensibilizando os educadores sobre a importância do entendimento do homem como espécie é desafiador. A oficina contou com 16 docentes participantes. A Figura 4 apresenta uma oficina aplicada com docentes da rede municipal de ensino do município de Acari-RN.

Figura 4 - Oficina com docentes da rede municipal de ensino, Acari-RN

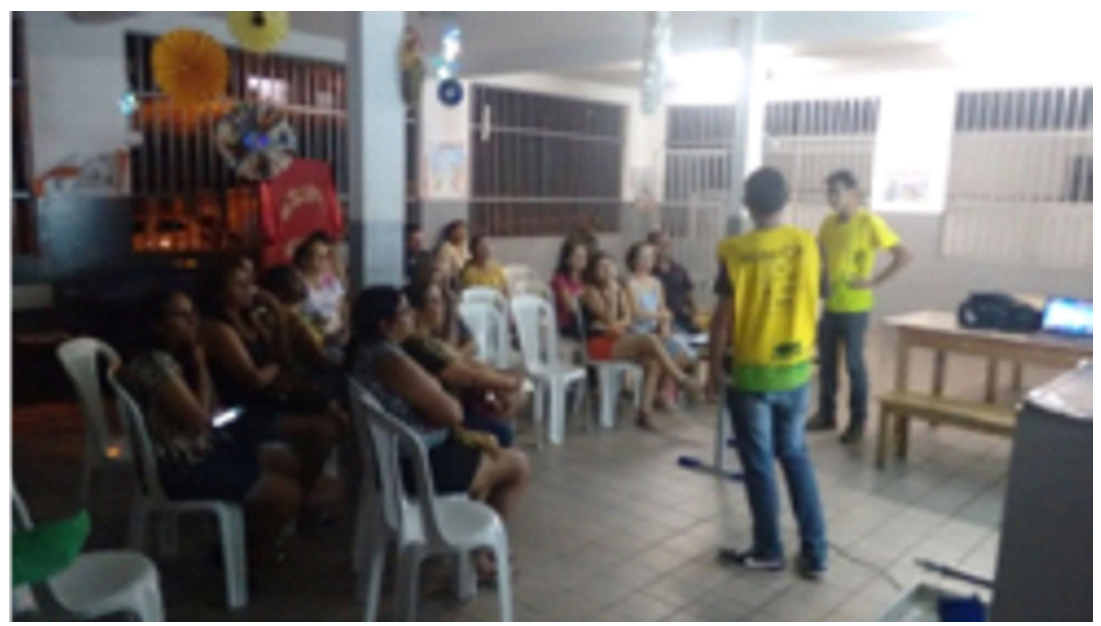

Fonte: Os autores (2016).

Assim, os educadores, em geral, não atribuem ao tema a devida importância ou se sentem despreparados para lidar com ele, como 
ressalta Reis Júnior (2003), para quem a EA tem sido tratada de forma pontual, restringindo-se aos livros didáticos, às datas comemorativas e ao plantio de hortas.

No projeto, os conceitos gerais sobre a EA foram apresentados com auxílio de recursos multimídias, tornando o assunto mais contextualizado por meio de imagens. Além disso, houve um diálogo construtivista acerca do tema, que possibilitou uma troca de experiências entre os professores e os rondonistas, assim agregando aprofundamento do tema. Logo, os docentes pesquisados representam socialmente a EA como um conjunto de práticas pedagógicas, cuja finalidade é o desenvolvimento de atitudes, valores e condutas em favor da preservação ambiental (SILVA; TEIXEIRA, 2015).

Portanto, é necessário que haja uma interlocução entre profissionais de diferentes áreas para consolidação das atividades a serem desenvolvidas sobre a EA, e de como ela pode transitar nas variadas disciplinas, com único objetivo de melhorar a conscientização para os alunos e comunidade em geral.

Na busca da conscientização, nada melhor do que expor os indivíduos ao contato direto com a natureza. Sair do ambiente da sala de aula oferece um novo panorama para trabalhar a EA com uma visão biocêntrica, sendo importante para instigar a curiosidade do quão fantásticas são as interações que acontecem ao redor do indivíduo. Ao ar livre, as oficinas trabalharam as características gerais sobre o meio ambiente, dando ênfase nos conceitos principais por meio de perguntas. Conforme a conversa ganhava forma, os interesses pelas novas descobertas só aumentavam. A Figura 5 apresenta uma oficina aplicada com alunos da rede municipal e de membros do grupo de escoteiros de Acari (RN). 
Figura 5 - Oficina com alunos ao ar livre, Acari-RN

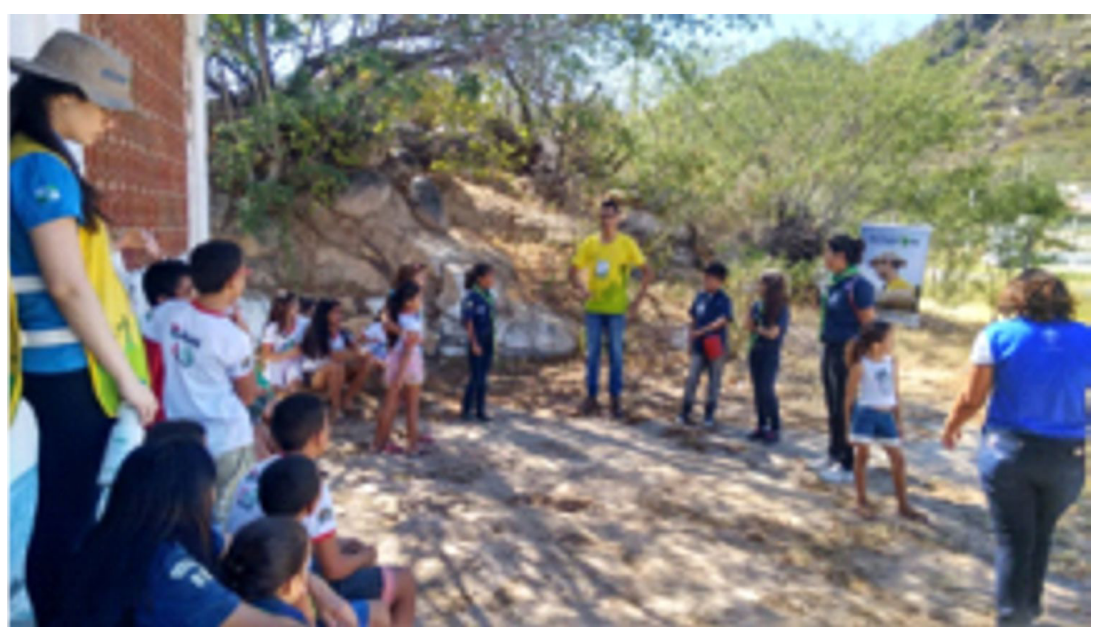

Fonte: Os autores (2016).

É relevante a utilização da fauna e flora local como material didático. Uma forma de aproveitar ao máximo as condiçóes que o próprio ambiente oferece. $\mathrm{Na}$ aula ao ar livre, exemplificamos como os cactos apresentam características morfofisiológicas diferentes das outras plantas, características essas resultantes de processos evolutivos da pressão seletiva mediante as condiçóes ecológicas da região. Tratamos também da importância dos insetos e o impacto que sua ausência pode ocasionar para a espécie humana.

Essa forma de trabalho corrobora com a ideia de que a EA não é uma disciplina estruturada e fixa, mas provinda de conhecimentos multidisciplinares que podem ser aplicados de inúmeras formas (MEDEIROS et al., 2011). Contudo, a aproximação dos indivíduos com a natureza cria um choque de realidade, pois quando se entende que o homem é um animal e que convive com os demais animais existentes no ecossistema, quebra-se o paradigma do pensamento antropocêntrico. Assim, é importante que dentro da EA seja instigado o estímulo de pensamento crítico referente ao nosso papel no ambiente, sensibilizando-nos para que reflitamos sobre nossas atividades, passando, assim, a respeitar os demais seres e recursos disponíveis. 


\section{CONSIDERAÇÕES FINAIS}

No interior do Sertão do Seridó potiguar, a pequena cidade de Acari vive um cenário entristecedor em decorrência da seca e da secagem do açude de Gargalheiras. Por isso, percebeu-se a relevância do assunto de meio ambiente, especialmente quanto aos recursos hídricos, abordado por meio da educação e de projetos de extensão, como o Projeto Rondon.

A participaçáo dos universitários na comunidade, por meio da extensão, possibilitou conhecer outra face da realidade social brasileira, que muitas vezes passa despercebida nas salas de aulas e na própria pesquisa científica. Além disso, participar de açóes extensionistas no interior do Rio Grande do Norte contribuiu para o desenvolvimento de um estudante universitário responsável e crítico frente à multiplicidade da realidade brasileira, no caso específico desse artigo, quanto à questáo ambiental em consonância com a sociedade local.

Os resultados mostraram que existe, minimamente, uma conscientização acerca da relação entre sociedade e meio ambiente em Acari, principalmente nos alunos do Ensino Médio e nos docentes, uma vez que eles tiveram contato direto com as duas situaçóes antagônicas que o município viveu recentemente: abundância versus escassez de água. Ao mesmo tempo, alguns alunos do ensino infantil e do fundamental demonstraram práticas ambientais questionáveis, como escovar os dentes com a torneira aberta e jogar lixo orgânico nas áreas de preservação. Logo, as oficinas instruíram na formação de seres pensantes como parte integral da natureza e não como algo superior.

A educação ambiental se mostra essencial para manter o equilíbrio natural, problematizando esse equilíbrio a partir das atividades humanas no meio ambiente. Difundir o conhecimento ambiental transcende o ambiente escolar, principal local de formação de ideias. A capacitação de profissionais não se restringe apenas à área biológica, mas em um universo multidisciplinar, podendo ser trabalhada nas demais ciências. Problematizar e contextualizar a questâo ambiental passa pela inovaçáo de como abordar a EA, requerendo um planejamento adequado e a criação de desafios.

A educação transforma o saber; ensinar o conteúdo de uma maneira 
ativa sobressai em melhores resultados. É preciso que os professores ultrapassem a zona de conforto e inovem suas atividades, visando uma conexão interdisciplinar para trabalhar a EA dentro e fora da sala de aula, pois, por meio da interdisciplinaridade, contextualiza-se o assunto de diversos panoramas, reforçando a ideia de que o meio ambiente é indispensável para qualquer indivíduo.

\section{REFERENNCIAS}

PREFEITURA MUNICIPAL DE ACARI. História e contexto atual. 2018. Disponível em: <http://www.acari.rn.gov.br/178/ DadosMunicipais/>. Acesso em: 12 mar. 2018.

AFONSO PINHEIRO, A. C.; CARVALHO, M. L. S. Economia e política agrícola. Lisboa: Ediçôes Sílabo, 2003. 328 p.

BRASIL. Constituição (1988). Constituição da República Federativa do Brasil. Brasília, DF: Senado Federal, 1988. 292 p.

. Lei no 6.938, de 31 de agosto de 1981. Dispóe sobre a Política Nacional do Meio Ambiente, seus fins e mecanismos de formulaçáo e aplicação, e dá outras providências. Disponível em: <http://www. planalto.gov.br/ccivil_03/Leis/L6938.htm>. Acesso em: 12 mar. 2018.

CORTEZ, A. T.; ORTIGOZA, S. A. G. (Org.). Da produçáo ao consumo: impactos socioambientais no espaço urbano. Sáo Paulo: Editora UNESP; São Paulo: Cultura Acadêmica, 2009. 146 p.

FLICKR. A. P. Fotos de Acari, Rio Grande do Norte. Disponível em: $<$ https://www.flickr.com/search/?user_id=53057644\%40N00\&view_ all=1\&text=acari $>$ Acesso em: 7 abr. 2018.

INSTITUTO BRASILEIRO DE GEOGRAFIA E ESTATÍSTICA - IBGE. Censo Demográfico de 2010. Disponível em: <www. censo2010.ibge.gov.br>. Acesso em: 4 abr. 2018.

JACOBI, P. Educação ambiental, cidadania e sustentabilidade. Cadernos de Pesquisa, São Paulo, n. 118, p. 189-206, mar. 2003. doi: https://dx.doi.org/10.1590/S0100-15742003000100008. 
MEDEIROS, A. B. et al. A importância da educação ambiental na escola nas séries iniciais. Revista Faculdade Montes Belos, Montes Belos v. 4, n. 1, set. 2011. Disponível em: <http://revista.fmb.edu. br/index.php/fmb/article/view/30>. Acesso em: 15 abr. 2018.

NUNES, A. L. P. F; SILVA, M. B. C. A extensão universitária no ensino superior e na sociedade. Mal-Estar e Sociedade, Barbacena, Ano IV, n. 7, p. 119-133, jul./dez. 2011. Disponível em: <http:// revista.uemg.br/index.php/malestar/article/view/60>. Acesso em: 15 abr. 2018.

PIANA, P. H. P. Alimentos geneticamente modificados e a construçáo do quadro regulatório no Brasil. 2013. 55 f. Monografia (Bacharel em Direito) - Faculdade de Ciências Jurídicas e Sociais do Centro Universitário de Brasília, Brasília, 2013.

PITOMBO, L. R. M.; LISBÔA, J. C. F. Sobrevivência humana: um caminho para o desenvolvimento do conteúdo químico no ensino médio. Química Nova na Escola, São Paulo, n. 14, 2001.

PROKOP, P.; TUNNICLIFFE, S. D. "Disgusting” animals: primary school children's attitudes and myths of bats and spiders. Eurasia Journal of Mathematics, Science \& Technology Education, London, v. 4, n. 2, p. 87-97, 2008. doi: https://dx.doi.org/10.12973/ ejmste/75309.

REIGOTA, M. Meio ambiente e representaçáo social. São Paulo: Cortez, 2002. 96 p.

REIS JÚNIOR, A. M. A formaçáo do professor e a educação ambiental. 2003. 177 f. Dissertação (Mestrado) - Faculdade de Educação, Universidade Estadual de Campinas, Campinas, 2003.

RIO GRANDE DO NORTE. Rio Grande do Norte: história, indicadores e fotos. 2018. Disponível em: <www.rn.gov.br>. Acesso em: 8 mar. 2018.

RODRIGUES, A. R. F.; LABURU, C. E. A educação ambiental no ensino de biologia e um olhar sobre as formas de relação entre seres humanos e animais. Revista Brasileira de Pesquisa em Educação em Ciências, Belo Horizonte, v. 14, n. 2, p. 171-184, 2014. Disponível em: <https://seer.ufmg.br/index.php/rbpec/article/view/2700/2066>. 
Acesso em: 15 mar. 2018.

RONDON. História do Projeto Rondon. 2018. Disponível em: <http://www.projetorondon.defesa.gov.br/portal/index/pagina/ id/9718/area/C/module/defaul> Acesso em: 8 de mar. 2018.

SANTOS, F. R.; SILVA, A. M. A importância da educação ambiental para graduandos da Universidade Estadual de Goiás: Campus Morrinhos. Interaçóes, Campo Grande, v. 18, n. 2, p. 71-85, 2017. doi: http://dx.doi.org/10.20435/inter.v18i2.1427.

SILVA, L. F; TEIXEIRA, E. S. Educação para a sustentabilidade: representações de educação ambiental em docentes de formação de professores. Revista de Ciências Humanas, Frederico Westphalen, v. 16, n. 27, p. 7-21, 2015. doi: http://dx.doi.org/10.31512/rch. v16i27.1501

SNADDON, J.; TURNER, E.; FOSTER, W. Children's perceptions of rainforest biodiversity: which animals have the lion's share of environmental awareness? Plos One, San Francisco, v. 3, n. 7, p. e2579, 2008. doi: https://doi.org/10.1371/journal.pone.0002579.

SORRENTINO, M. et al. Educação ambiental como política pública. Educação e Pesquisa, São Paulo, v. 31, n. 2, p. 285-299, maio-ago. 2005. doi: https://doi.org/10.1590/S1517-97022005000200010

SOUSA, R. G. et al. Meio ambiente e insetos na visão de educandos de $6^{\circ}$ e $8^{\circ}$ ano de escolas públicas em Anápolis-GO. Ambiente $\&$ Educação, Rio Grande, v.18, n. 2, 2013. Disponível em: <https:// periodicos.furg.br/ambeduc/article/view/3244>. Acesso em: 10 abr. 2018.

SOUSA, R. G.; SANTOS, M. L. Percepção ambiental dos usuários da Fazenda Santa Branca Ecoturismo (APA - Ribeirão João Leite), Teresópolis-GO. Revista Brasileira de Ecoturismo, São Paulo, v. 3, n. 3, p. 460-477, 2010. Disponível em: <http://www.sbecotur.org. br/rbecotur/artigos/abstract38.pdf>. Acesso em: 15 abr. 2018.

STEARNS, S. Life history evolution: successes, limitations, and prospects. Naturwissenschaften, v. 87, n. 11, p. 476-486, 2000. doi: https://dx. doi.org/10.1007/s001140050763 
UNESCO. Década da educação das Naçóes Unidas para um desenvolvimento sustentável, 2005-2014: documento final do plano internacional de implementação. Brasília: Unesco, 2005. 120 p.

Submetido em 12 de abril de 2018.

Aprovado em 6 de julho de 2018. 